\title{
Endothelial Cells Induce Proliferation and Bone Morphogenic Protein Mediated Differentiation of Pdgfra+ Human Oligodendrocyte Precursor Cells to Astrocytes in Trans-Well Co-Culture
}

Asmita Dasgupta ( $\nabla$ asmitadgupta.bbm@pondiuni.edu.in )

Pondicherry University https://orcid.org/0000-0001-6652-0728

\section{Research Article}

Keywords: Oligodendrocyte progenitors, Oligodendrocyte, Astrocyte, Differentiation, Endothelial cell, Trans-well co-culture

Posted Date: February 28th, 2022

DOI: https://doi.org/10.21203/rs.3.rs-850528/v2

License: (c) (i) This work is licensed under a Creative Commons Attribution 4.0 International License. Read Full License 


\section{Abstract}

CD140a /PDGFRa + human oligodendrocyte precursor cells (hOPCs) are demonstrated to have significant potential in cell therapy against demyelinating diseases. However, little is known about the contribution of human endothelial cells in the biology of PDGFRa + hOPCs in the stem cell niche. Hence trans-well coculture technique with human umbilical vein endothelial cells (HUVECs) was adopted under proliferative or differentiating conditions to understand the role of endothelial cells in these processes within PDGFRa + hOPCs. In co-culture with HUVECs, under proliferative conditions, the hOPCs show increased proliferation and sphere formation. In contrast, under differentiating conditions, the hOPCs show increased differentiation to astrocytes, with a concomitant decrease in differentiation to oligodendrocytes, compared to no co-culture controls. Transcript assay for selected humoral factors in the hOPCs and HUVECs revealed bone morphogenic proteins (BMPs), endothelin1, growth arrest specific 6 (GAS6), and interleukin 6 (IL6) to be in higher abundance in HUVECs than hOPCs. Further, Noggin was tested and found to effectively attenuate HUVEC mediated astrocytic differentiation of CD140a /PDGFRa + fetal hOPCs, confirming the astrocytic differentiation of these hOPCs to be a BMP mediated process. Hence, the study concludes that human endothelial cells can induce increased proliferation and BMP mediated astrocytic differentiation of PDGFaR + hOPCs. Based on effect of noggin on differentiation outcome of PDGFRa + hOPC, it is conjectured that co-administering pharmacological inhibitors of BMP signaling along with PDGFRa + hOPC transplantation may make these cells more effective in remyelination therapy.

\section{Introduction}

Among the cells that constitute the niche, the vasculature forms an integral part $[1,2]$. Vasculature and neurons mutually support each other mediated by brain derived neurotrophic factor and vascular endothelial growth factor respectively during adult neurogenesis $[3,4]$. Vascular endothelial cells also stimulate the self-renewal of neural stem cells (NSCs) and expand neurogenesis within in vitro murine systems [5]. The role of diffusible factors from endothelial cells is significant in the biology of the neurogenic niche since the endothelial contacts with NSCs in the sub-ventricular zone are frequently devoid of astrocytic endfeet or pericyte sheath and thus are unusually permeable [6]. Vasculature also acts as scaffolds for migration of Olig2 + PDGFRa + human oligodendrocyte precursor cells (OPCs) during 18-24 gestational weeks [7]. While little is known on the contribution of human vascular endothelial cells on proliferation, maintenance and differentiation of the human OPCs [6, 7], subtle interspecies differences are recognized [8].

The hypothesis behind this study is that the soluble factors from human endothelial cells would support human OPC proliferation and their differentiation to oligodendrocytes. Oligodendrocyte precursors identified by sequential stage specific surface antigens including, but not limited to, the transmembrane proteoglycan NG2, cell surface ganglioside epitope A2B5, PDGFRa, CD9, 04/sulfatide, and 01/galactocerebroside, can all mature to committed oligodendrocytes [9]. Most of these OPCs however are bi-potential, differentiating to both oligodendrocytes and astrocytes as evidenced using transgenic 
lines of genetically marked OPCs [10]. Even the more mature OPCs expressing 04 sulfatide differentiate to both oligodendrocytes and astrocytes $[11,12]$. However, in trans-well co-culture with dorsal root ganglia, the 04 + OPCs become unipotent towards oligodendrocytes [12], showing that OPC differentiation outcome is influenced by niche associated soluble factors making it necessary to understand the influence of endothelial cells on the PDGFRa + human OPCs (hOPCs).

Early OPCs isolated by immune selection using A2B5 monoclonal antibody [13] have a greater advantage in transplantation-based cell therapy because of their ability to migrate away from the site of injection to achieve remyelination in the hypomyelinated brains of shiverer mouse $[14,15]$. Intermediate OPCs expressing PDGFRa also successfully re-myelinate the same shiverer mouse brains $[16,17]$, demonstrating their therapeutic potential. However, just like the mature $04+\mathrm{OPCs}$, the early A2B $5+$ and intermediate PDGFRa + OPCs are bi-potential. The effect of astrocytes on remyelination is complex with both favorable and unfavorable roles known [18]. Both normal as well as reactive astrocytes inhibit differentiation of OPCs to oligodendrocytes during spinal cord injury and promote astrocytic differentiation in a bone morphogenic protein (BMP) dependent manner [19]. Hence, differentiation of OPCs to astrocytes may not be a favorable outcome towards remyelination therapy.

The present study aims to explicate the potential roles of diffusible factors of endothelial cells as human umbilical vein endothelial cells (HUVECs) in survival, proliferation, and differentiation of CD140a/PDGFRa + fetal human OPCs (hOPCs) using trans-well co-culture technique. The findings establish that the soluble factors from the human endothelial cells induce replication and proliferation of the hOPCs and induce their BMP mediated differentiation to astrocytes.

\section{Materials And Methods}

\section{Human Oligodendrocyte Precursor Cells}

All experimental methods were carried out using protocols approved by the University of Rochester, Institutional Review Board/Research Subjects Review Board (IRB/RSRB approval \# 26905). For this study, 15 brain tissues were obtained after deidentification of aborted fetuses between 18-23 gestational weeks (gw) by the surgical pathology and considered exempt by IRB/RSRB. The cortical specimens were collected and dissociated within less than two hours post mortem using papain and DNase as per established protocols $[13,14]$. Cells were plated at $2 \mathrm{million} / \mathrm{ml}$ in serum-free media (SFM) containing DMEM/F12/N1 with $20 \mathrm{ng} / \mathrm{ml}$ of fibroblast growth factor 2 (FGF2) overnight. Complete composition of SFM is given in Supplemental Table S1. Dissociated cells were recovered the following day, counted, and sorted by magnetic cell sorting for PDGFRa+ hOPCs, using primary antibody against PDGFRa, CD140a, (BD Pharmingen) and rat secondary anti-mouse lgG2a+b conjugated Microbeads (Miltenyi Biotech) [14]. After sorting, the purity of the sort was verified by FACS analysis and PDGFRa+ hOPCs were either frozen for isolation of total mRNA or seeded in SFM as defined for proliferative or differentiating conditions for co-culture with HUVECs.

\section{Human Umbilical Vein Endothelial Cells}


The Human Umbilical Vein Endothelial Cells (HUVECs) purchased from the Department of Microbiology and Immunology, University of Rochester Medical Center in their early (second) passage were maintained on $0.2 \%$ gelatin-coated tissue culture flasks in DMEM/F12, $10 \%$ PD-FBS, $10 \mathrm{ng} / \mathrm{ml}$ of FGF2 and $25 \mathrm{ng} / \mathrm{ml}$ of VEGF. The cells were passaged every 5-7 days with $0.05 \%$ Trypsin/EDTA with 1:4 splitting and used within passage 3-5 for total mRNA isolation and co-culture with OPCs.

\section{Co-culture}

For hOPC-HUVEC co-culture, PDGFRa+ hOPCs in 17500 numbers/well were seeded directly post sort in 24-well plates on defined substrate, and SFM for either proliferative or differentiating condition and 15000 HUVECs were seeded on $0.2 \%$ gelatin-coated trans-well inserts with $0.4 \mu \mathrm{m}$ pore size.

\section{Proliferative condition}

OPCs were seeded onuntreated 24-well suspension plate in SFM with $20 \mathrm{ng} / \mathrm{ml} \mathrm{FGF2,} \mathrm{20ng/ml} \mathrm{PDGF-AA}$ for co-culture for up to 28 days, with a change in the trans-well insert every 5-7 days up to 28 days for the remaining plates. Plates were withdrawn for assessment of OPC sphere formation each week using protocols detailed in Supplemental Experimental Procedures.

\section{Differentiating condition}

OPCs were seeded on poly-ornithine-laminin coated 24-well adherent plates, maintained in SFM with $25 \mathrm{ng} / \mathrm{ml}$ VEGF to support the HUVECs with alternate-day media change. At the end of 4 and 7 days, the hOPCs were fixed for immunocytochemistry for 04 and GFAP.

\subsubsection{Inhibition of differentiation}

OPCs were pretreated with $100 \mathrm{ng} / \mathrm{ml}$ recombinant human Noggin ( $\mathrm{R} \& \mathrm{D}$ Systems) $4 \mathrm{~h}$ before starting coculture to inhibit all endogenous BMP signaling and re-treated every $24 \mathrm{~h}$ thereafter. At the end of 4 and 7 days, the cells were fixed, and immunocytochemistry was performed for 04 and GFAP.

\section{Immunocytochemistry}

Immunocytochemistry for checking differentiation outcome of OPCsto oligodendrocytes or astrocyteswith or without co-culture was doneafter 4 or 7 days for cells, and at the end of $2 \mathrm{~h}$ or $4 \mathrm{~d}$ after re-plating the spheres for differentiation. Antibody-specific protocols for primary antibodies against PDGFRa, A2B5, NG2, Olig2, GFAP, $\beta$ - III tubulin, and 04 are described in the Supplemental Experimental Procedures. The differentiation experiment was performed five times, and the inhibition of differentiation was performed four times with biological replicates, each with triplicate wells for with or without HUVECs co-culture and counts presented as mean \pm standard error (SE).

\section{Thymidine Incorporation Assay}


Under proliferative conditions, OPC cultures were pulsed with $1 \mu \mathrm{Ci}$ of (Methyl- ${ }^{3} \mathrm{H}$ ) - Thymidine per ml of media for $72 \mathrm{~h}$ in quadruplicate wells with or without co-culture. After incubation, the cells were washed with Hank's solution, DNA precipitated with ice-cold $5 \%$ (wt. /vol.) trichloroacetic acid for 20 min at $4^{\circ} \mathrm{C}$, and solubilized in $0.55 \mathrm{ml}$ of $0.3 \mathrm{M}$ sodium hydroxide $-0.1 \%$ sodium dodecyl sulfate for $1-2 \mathrm{~h}$ at $37^{\circ} \mathrm{C}$. Half milliliter of this cell extract was added to $5 \mathrm{ml}$ of Ecoscint A scintillation cocktail, and radioactivity measured in a Beckman Coulter LS 6500 Liquid Scintillation Counter for 1 minute. The experiment was repeated with three biological replicates, in quadruplicate wells each, for co-culture and no co-culture condition. Data was expressed as mean \pm SE cpm/well.

\section{RNA Preparation and Gene Expression Assay}

Total RNA was extracted from PDGFRa+ OPCs (four biological replicates), and HUVECs (three biological replicates), that had been snap-frozen directly post-sort and post-passage respectively, using RNeasy Mini kit (Qiagen) for Animal Cells with "on column" DNase digestion. Total RNA was reverse transcribed using the Reverse Transcription reagents (Applied Biosystems), random hexamers, and MultiScribe ${ }^{\text {TM }}$ Reverse Transcriptase (RT). Inventoried TaqMan ${ }^{\circledR}$ Gene Expression Assay were performed individually for 15 genes of relevant soluble factors or their receptors in reaction mix containing $5 \mathrm{ng}$ of cDNA, 900nM forward and reverse primers, 250nM FAM-labeled MGB probes, and TaqMan® Universal PCR Master Mix in triplicate wells. List of Inventoried TaqMan ${ }^{\circledR}$ Gene Expression Assays IDs is given in Supplemental Table S2. The thermal cycle was run on ABI Prism 70000 for 2 min at $50^{\circ} \mathrm{C}, 10 \mathrm{~min}$ at $95^{\circ} \mathrm{C}$, followed by 40 cycles of $15 \mathrm{sec}$ at $95^{\circ} \mathrm{C}$ and $2 \mathrm{~min}$ at $60^{\circ} \mathrm{C}$. Human GAPDH (FAM / MGB Probe, Non-Primer Limited) was used as endogenous control. No RT control was performed for each RNA sample for every assay. Gene expression was determined in HUVECs and OPCs relative to their respective endogenous GAPDH by delta $\mathrm{C}_{\mathrm{T}}$ method. HUVEC to hOPC differential expression fold ratio (FR) was calculated and the significance determined by t-test statistics. Heat map for mean expressions was constructed on Prism 8. Raw Ct values for the TaqMan Assays are given in Supplemental Spreadsheet 1.

\section{Network Analysis}

Differential molecular networks were generated for co-culture and no co-culture environment using gene lists relevant to the two conditions consisting of the phenotypic marker genes used in sorting and immunocytochemistry and the soluble factor genes assessed in Taqman assays. While both the coculture and no co-culture gene lists contained the same list of phenotypic markers and the soluble factors relatively over-expressed by the OPCs, the gene list for co-culture environment additionally also contained the humoral factors over-expressed by HUVECs relative to OPCs in gene expression assay. The Input Gene-lists for Differential Network Analysis are given in Supplemental Table S3. Differential networks were generated for the two gene lists on PCViz2 application [20] of Pathway Commons [21]. Network BioPAX [22] files were, opened on Cytoscape 3.4.0 [23] for identification of major subnetworks, generation of difference network and statistical visualization of nodes based on prevalence and connectivity. Complete list of nodes and edges for all three networks are given in Supplemental Spreadsheet 2. 


\section{Statistical Analysis}

Statistical analysis was performed on Prism, GraphPad Software, CA. Two-way repeated measures ANOVA, followed by Bonferroni's correction of p-values, was used for determining significance of differences in sphere count, sphere size, thymidine incorporation, cell numbers post-sphere-dissociation, and the effect of co-culture on 04 and GFAP expression by OPCs. One-way ANOVA followed by NeumanKeul's multiple comparison post-test was used for evaluating the effect of Noggin to attenuate astrocytic differentiation of OPCs in co-culture. Student's t-test for samples with equal variance was used for determining significance in gene expression assays. The differences were considered statistically significant, when P-value was less than 0.05. Data are presented as mean \pm SE except for gene expression assays where it is reported as mean \pm standard deviation (SD).

\section{Results}

\section{Endothelial cells encourage sphere formation in PDGFRa+ oligodendrocyte precursor cells}

To determine the effect of endothelial cell derived soluble factors on the oligodendrocyte precursor cells, the hOPCs were maintained under proliferative conditions in co-culture with HUVECs on trans-well for four weeks. Trans-well insert was changed every 5-7 days. It was observed that OPC spheres originated as adherent spheres by clonal expansion. These spheres were more in number and of larger diameter when the hOPC were in co-culture with the HUVECs compared to those without co-culture. A minimum hOPC sphere was visually perceived consisting of approximately eight cells. After three weeks in culture, hOPC spheres grew too large to be held to the substrate, and they would detach and stay close to the surface of the plate. At this stage, the spheres also showed a tendency to gather and fuse, forming mega-spheres. There was always a significant difference in the number of spheres and the diameter of the largest sphere between co-culture and no-co-culture conditions (Fig. 1A). The co-culture effect was highly significant $(P<0.0001)$, and the increase in sphere numbers was also a function of time $(P<0.0001)$ (Fig. 1B). In the same experiment, when the diameter of the largest sphere was measured every week for wells with and without HUVEC co-culture, the co-culture effect was highly significant, with $\mathrm{P}<0.0001$ and along with the time effect with $\mathrm{P}<0.0001$ (Fig. 1C). Thus, co-culture with HUVECs encouraged survival or proliferation or both for the PDGFRa+ OPCs.

\section{Endothelial cells induce proliferation in PDGFRa+ human oligo progenitors}

To determine if co-culture with endothelial cells encouraged the proliferation of progenitors, hOPCs were allowed to grow up to four weeks with or without co-culture. When cell numbers in hOPC spheres were determined by dissociating them with papain/DNase at 7, 14, 21, and 28 days, effect of HUVEC co-culture on the increase in hOPC cell number was significant with $P=0.0013$. The difference in cell numbers between the co-culture and no co-culture group was significant at 21-day $(t=6.208, p<0.001)$ and 28-day $(t=8.991, p<0.001)$ time points. Independent of the co-culture, the cell numbers also increased as a function of time with a $\mathrm{P}<0.0001$ (Fig. 2A). Synthesis of new chromatin material should accompany increased proliferation. To assess the net proportion of active DNA synthesis, when the hOPCs in 
quadruplicate wells with or without co-culture were pulsed for 72 hours with [ ${ }^{3} \mathrm{H}$ - methyl] thymidine at 4 , 12,18 , and 25 days, thymidine incorporation in the OPCs showed that the effect of co-culture was significant with $\mathrm{P}=0.0052$. Again, the effect was significant at only21-day $(t=3.995, p<0.01)$ and 28 -day $(t=8.819, p<0.001)$ time points and not at 7 and 14 days. The effect of time was also highly significant with $\mathrm{P}<0.0001$ (Fig. 2B).

\section{Co-culture does not alter differentiation outcome of the hOPC spheres}

To determine if the hOPCs in co-culture generated in the proliferative conditions had more oligogenic potential, human OPC spheres formed at the end of each week of culture in proliferative conditions with or without co-culture with HUVECs were re-plated and incubated in differentiation conditions for $2 \mathrm{~h}$ to 4 days. The differentiated spheres were then stained for common progenitor and differentiation markers PDGFRa, A2B5, NG2, Olig2, 04, GFAP, and $\beta$ III tubulin (Fig. 2C). Fluorescence micrographs show that the distribution of these markers is not significantly different between the spheres arising from co-culture and no co-culture conditions. However, there were always minor differences in the distribution of markers between sphere to sphere within the same condition. Thus, irrespective of co-culture, some spheres were remarkably rich in 04 or GFAP compared to the other spheres in the same well, indicating preservation of asymmetric division of the progenitors under proliferative conditions irrespective of co-culture. In addition, regardless of co-culture, $\mathrm{O} 4$ expression and its clonal expansion from the PDGFRa+ OPCs could be seen only up to the first two weeks in these experiments, during which some spheres gave rise to a greater number of 04 positives than others within the same well. At the end of four weeks in vitro, irrespective of co-culture, the PDGFRa+ hOPC spheres upon re-plating were mostly A2B5 positive (50 to $75 \%$ ) and GFAP positive (70 to $85 \%$ ), with minimal (3 to $6 \%$ ) 04 positive cells.

\section{Endothelial cells induce differentiation of hOPCs to Astrocytes}

To examine if co-culture with HUVECs could affect the differentiation pattern of the oligodendrocyte precursors independent of their proliferation, PDGFRa+ hOPCs were seeded directly under differentiating conditions and incubated for either 4 or 7 days. Differentiation of the OPCs to oligodendrocyte and astrocyte lineages were assessed by immunocytochemistry for differentiation markers 04 and GFAP respectively (representative micrographs in Fig. $3 \mathrm{~A}$ ). Counting the immuno-stained cells revealed that the percent of oligodendrocytes as determined by 04 staining decreases significantly upon co-culture with $\mathrm{P}=0.0351$, with the decrease in the 04 percentage at seven days being significant $(t=2.730, p<0.05)$ though the difference at four days was not significant (Fig. 3B). Time had no significant effect on the 04 survival within this one week. Co-culture very significantly caused induction of astrocytic lineage as measured by the percent of GFAP positive cells, $\mathrm{P}=0.0082$, with a $26 \%$ astrocytic induction at four days $(t=2.894, p<0.05)$, and $31.66 \%$ at seven days $(t=3.500, p<0.01)$. GFAP induction in these cultures also significantly increased with time, with $P=0.0001$ (Fig. 3C). Thus, co-culture with endothelial cells encourages astrocytic differentiation of the PDGFRa+ hOPCs with a concomitant decrease in differentiation to oligodendrocytic lineage. 


\section{Transcriptional analysis of HUVECs and hOPCs reveal predominant soluble mediators}

The relative contribution of soluble factors from HUVECs and PDGFRa+ hOPCs to the co-culture environment was assessed by measuring the expression levels of 15 relevant genes using Inventoried Taqman's human Gene Expression Assay. Fold ratio (FR) for gene expression was calculated for HUVEC to hOPC with respect to the respective endogenous GAPDH using delta $\mathrm{C}_{\mathrm{T}}$ method. Fig. $4 \mathrm{~A}$ shows the gene expression in each biological replicate as mean expression in three technical replicate assays. Heat map of mean expression ratio with respect to endogenous GAPDH in HUVECs and PDGFRa+ hOPCs is shown in the inset; Fig. 4B. HUVEC to hOPC fold ratio (FR) of gene expression is given in Table 1. Of all the 15 genes tested for, the highest difference in mRNA expression relative to GAPDH was observed for bone morphogenic protein 4 (BMP4), with HUVEC to hOPC expression FR=134.9 $(p=0.0026)$. HUVECs also showed increased expression of bone morphogenic protein $6(B M P 6)$ with $\mathrm{FR}=4.211(p=0.00071)$ and endothelin1 (EDN1) with FR=41.50 ( $p=0.00101)$. Growth arrest specific 6 (GAS6) had FR=3.753 ( $p=$ $0.02363)$ and interleukin6 (IL6) had FR=3.726 ( $p=0.00296)$, both showing higher expression in HUVECs than the hOPCs. Endothelin1 receptor B (EDNRB) was significantly more abundant in PDGFRa+ OPCs than HUVECs. The other endothelin1 receptor EDNRA did not show any significant difference in expression between two cell types. Transcripts of soluble factors more abundant in OPCs compared to HUVECs includes Pleiotrophin (PTN) with FR=0.003612 ( $p=0.01972)$, followed by fibroblast growth factor 9 (FGF9) or glia activating factor, with $\mathrm{FR}=0.004552(p=0.02482)$, and cytokines as, ciliary neurotrophic factor (CNTF), and leukemia inhibitory factor (LIF), with FR of $0.032551,(p=0.00710)$, and 0.048426 $(p=0.00235)$ respectively. Other humoral factor genes that did not show differential expression between the two cell types were the bone morphogenic proteins 2 and 5 (BMP2 and BMP5) and the fibroblast growth factor -2 (FGF2). Raw Ct values for these experiments are given in Supplemental Spreadsheet 1.

TABLE 1 Relative mRNA Expression of selected soluble factors and receptors in terms of HUVEC to hOPC Fold Ratio by Taqman Gene Expression Assaya 


\begin{tabular}{|c|c|c|c|c|c|c|}
\hline \multirow[t]{2}{*}{$\begin{array}{l}\text { HGNC Gene } \\
\text { Symbol }\end{array}$} & \multirow{2}{*}{$\begin{array}{l}\text { HGNC } \\
\text { Full Name }\end{array}$} & \multirow{2}{*}{$\begin{array}{l}\text { Entrez } \\
\text { Gene } \\
\text { ID }\end{array}$} & \multirow{2}{*}{$\begin{array}{l}\text { HUVEC to } \\
\text { hOPC } \\
\text { Fold Ratio } \\
\text { (FR) }\end{array}$} & \multicolumn{2}{|c|}{$\begin{array}{l}\text { Significantly More } \\
\text { Abundant in }\end{array}$} & \multirow{2}{*}{$\begin{array}{l}p \\
\text { values } \\
(n=7)\end{array}$} \\
\hline & & & & $\begin{array}{l}\text { HUVECs } \\
(n=3)\end{array}$ & $\begin{array}{l}\text { hGPCs } \\
(n=4)\end{array}$ & \\
\hline \multicolumn{7}{|c|}{ Bone Morphogenic Proteins } \\
\hline BMP2 & $\begin{array}{l}\text { bone morphogenetic } \\
\text { protein } 2\end{array}$ & 650 & 0.628235 & & & 0.19476 \\
\hline BMP4 & $\begin{array}{l}\text { bone morphogenetic } \\
\text { protein } 4\end{array}$ & 652 & 134.9001 & Yes & & 0.00264 \\
\hline BMP5 & $\begin{array}{l}\text { bone morphogenetic } \\
\text { protein } 5\end{array}$ & 653 & 0.023848 & & & 0.10684 \\
\hline BMP6 & $\begin{array}{l}\text { bone morphogenetic } \\
\text { protein } 6\end{array}$ & 654 & 4.211436 & Yes & & 0.00071 \\
\hline BMP7 & $\begin{array}{l}\text { bone morphogenetic } \\
\text { protein } 7\end{array}$ & 655 & NA & & & NA \\
\hline
\end{tabular}

Fibroblast Growth Factors

\begin{tabular}{|llllll}
\hline FGF2 & $\begin{array}{l}\text { fibroblast growth } \\
\text { factor 2 }\end{array}$ & 2247 & 1.747718 & & 0.22904 \\
\hline FGF9 & $\begin{array}{l}\text { fibroblast growth } \\
\text { factor } 9\end{array}$ & 2254 & 0.004552 & Yes & 0.02482 \\
\hline
\end{tabular}

Cytokines

\begin{tabular}{lllllll} 
IL6 & interleukin 6 & 3569 & 3.726636 & Yes & & 0.00296 \\
\hline LIF & $\begin{array}{l}\text { leukemia inhibitory } \\
\text { factor }\end{array}$ & 3976 & 0.048426 & Yes & 0.00235 \\
PTN & Pleiotrophin & 5764 & 0.003612 & Yes & 0.01972 \\
\hline
\end{tabular}

Other Humoral Factors

\begin{tabular}{lllllll} 
GAS6 & growth arrest-specific & 2621 & 3.753718 & Yes & & 0.02363 \\
\hline EDN1 & endothelin 1 & 1906 & 41.49811 & Yes & & 0.00101 \\
\hline CNTF & $\begin{array}{l}\text { ciliary neurotrophic } \\
\text { factor }\end{array}$ & 1270 & 0.032551 & & Yes & 0.00710 \\
\hline
\end{tabular}

Endothelin Receptors

\begin{tabular}{llllll} 
EDNRA & $\begin{array}{l}\text { endothelin receptor } \\
\text { type A }\end{array}$ & 1909 & 0.045506 & & 0.08647 \\
\hline EDNRB & $\begin{array}{l}\text { endothelin receptor } \\
\text { type B }\end{array}$ & 1910 & 0.011111 & Yes & 0.03155 \\
\hline
\end{tabular}


Note: a For the expression assay, 5ng of cDNA for each HUVEC $(n=3)$ and hGPC $(n=4)$ sample was loaded in triplicate wells for the Inventoried TaqMan® Gene Expression Assays, the Assay IDs for which are described in Table S1. For each gene, the HUVEC to hGPC expression fold ratio was determined by delta $\mathrm{C}_{\mathrm{T}}$ method after normalizing the expression to endogenous GAPDH. BMP7was not detected in HUVECs during the assay and hence the fold ratio for BMP7 is not available (NA). Statistical significance was determined by t test for samples with equal variance. $p<0.05$ was considered significant.

\section{Network Analysis reveals BMP4 as the key differentiation factor}

Knowledge-based networks were built using gene-lists specific to the co-culture and no co-culture environments on the PCViz2 application of Pathway Commons with Input Gene-lists for Differential Networks given in Table S2. The networks were analyzed with Cytoscape 3.4.0. and represented with statistical weightage of molecular interactions at the nodes as well as the edges for no co-culture and coculture conditions (Fig. 5A, B). The difference network between the co-culture and no co-culture environments (Fig. $5 \mathrm{C}$ ) revealed BMP4 as the predominant node with the most connections, followed by EDN1, BMP6, IL6 and GAS6 closely matching the experimental FRs of transcripts in HUVECs to hOPCs determined by Taqman Assay. The complete list of nodes and edges for all three networks are given in Supplemental Spreadsheet 2.

\section{Noggin can inhibit HUVEC induced differentiation of hOPCs to Astrocytes}

Based on the relative fold ratios of the transcripts seen in gene expression assay (Table 1, Fig. 4), and the knowledge-based networks (Fig. 5), bone morphogenic protein 4 (BMP4) was hypothesized to be the most significant humoral factor from HUVECs in co-culture media that could affect the differentiation fate of hOPCs. If the astrocytic differentiation of the PDGFRa+ OPCs in co-culture with HUVECs is mediated by the BMPs, the same should be attenuated by noggin, the general inhibitor of BMP signaling. Therefore, PDGFRa+ hOPCs were plated for differentiation with a pre-treatment by $100 \mathrm{ng} / \mathrm{ml}$ of Noggin for $4 \mathrm{~h}$ to block all endogenous BMP signaling, followed by the start of co-culture with HUVECs. The Noggin treatment was repeated every 24 hours until 4 and 7 days, followed by immunocytochemistry for $\mathrm{O} 4$ and GFAP to assess commitment to oligodendrocyte or astrocyte lineage, respectively. Representative micrographs are presented in Fig. 6A. Statistical analysis of the cell counts by one-way ANOVA revealed that Noggin could effectively reduce HUVEC induced astrocytic differentiation at both 4- and 7-day time points with $P=0.0012$. Effective lowering of the percent of GFAP positive cells for co-culture was from $56.27 \pm 5.085$ (mean \pm SE) without Noggin to $25.21 \pm 4.814$ with Noggin $(p<0.01)$. While in the absence of co-culture, only $37.83 \pm 4.042$ percent of human OPCs showed GFAP expression under identical conditions $(p<0.05))$. On day 7 , the daily noggin treatment continued to attenuate HUVEC mediated astrocytic differentiation with a similar statistical pattern (Fig. 6 B). Since HUVEC mediated astrocytic differentiation of PDGFRa+ hOPCs was completely attenuated by Noggin, the endothelial mediated astrocytic differentiation of hOPCs was concluded to be BMP mediated.

\section{Discussion}


PDGFRa positive human oligo-progenitors are of considerable therapeutic potential $[16,17]$ and hence the role of the endothelial cells in the biology of PDGFRa + OPCs is of significant interest. As summarized in Fig. 7, the present study demonstrates that trans-well co-culture of HUVECs with human PDGFRa + OPCs encourage increased proliferation of the OPCs, and their increased BMP induced differentiation to astrocytes which can be reversed by the general BMP inhibitor, noggin. The results demonstrate the bipotential nature of the PDGFRa + human OPCs by underlining its BMP mediated astrocytic differentiation. Nevertheless, astrocytic differentiation of these OPCs does not come as a surprise because PDGF signaling activation is widely implicated in astrocytic brain tumors [24, 25], and PDGFRa positive progenitor cells have been associated with the early changes associated with tumor initiation [26]. PDGFRa expressing stromal cells derived from oligodendrocytes progenitor cells are found at the invasive front of high-grade gliomas, exhibiting a unique perivascular distribution indicating that the interaction of these cells with the endothelial partners are of significance towards tumor origin or expansion [27]. There are reports of heterogeneity in murine derived PDGFRa + OPCs with some of these cells overlapping with the endothelial cells giving rise to pericytes $[28,29]$ however curiously these reports do not explore the differentiation of PDGFRa + OPCs to astrocytic lineage. Also, other reports use PDGFR $\beta$ as a marker for pericytes instead [30]. In zebrafish, the OPC identified by olig1 have been genetically labelled and followed to generate functionally diverse OPC subgroups in their response to neurons and activity regulates the proliferation of a subset of OPCs that fulfil the functions similar to that of astrocytes in the mammalian brains and thus are distinct from the cells that generate differentiated oligodendrocytes [31]. This almost reiterates the bipotential nature of these OPCs.

The gestational age of the fetus from which the hOPCs are isolated for the experiments are ruled out from being a confounding factor in these observations, since PDGFRa + progenitors derived from 15$23 \mathrm{gw}$ are known to exhibit an age-dependent increase in early to mid-stage lineage markers, including 04 sulfatides and Olig2 [32]. Hence, identifying unipotent OPCs could be a possible solution against the astrocytic differentiation of OPCs. Towards this, tetraspannin could be a preferred marker, since tetraspannin expression promotes oligodendrocyte differentiation [33]. Hence PDGFRa + OPCs that coexpress pro-oligodendroglial tetraspannin CD9 could be more lineage restricted [33,34]. However, cues as fibrinogen following vascular damage induce BMP signaling even in more mature $04+$ OPCs to increase astrocytic differentiation, and decrease re-myelination [11]. Hence, the search for unipotent OPCs could be elusive. Instead, better understanding of the influence of the components of the oligogenic niche on OPC differentiation could be necessary in designing of remyelination therapy.

Endothelial interactions are of fundamental importance in oligovascular niche as fate of the OPCs depend upon the soluble factors to which they get exposed [35], that includes endothelial-derived factors. The effects of human endothelial- human OPC interactions as observed here agree with reports on oligovascular niche using murine OPCs with mouse brain endothelial cells [36] or human brain microvasculature derived endothelial cells [37] implicating BMPs as inhibitors of oligodendrocyte development and promoters of astrocyte development, with the BMP inhibitor noggin having the opposite effect [38-41]. The novel aspect of this study is that it is the first report of trans-well co-culture interaction of human derived endothelial cells with human derived PDGFRa + OPCs and the observed effects are that 
of proliferation of the OPCs and their BMP mediated astrocytic differentiation. The previous study [37] performed with human endothelial cells used murine derived OPCs in co-culture, and thus this is the first humanized study of endothelial oligodendrocyte progenitor interaction. Anatomy of stem cell niche encourages interactions of the laminin-containing extracellular matrix of endothelial cells with the a6 $\beta 1$ integrin on stem cells, to inhibit stem cell proliferation within the niche [1]. Adhesion to the vasculature is also the key to directed migration of the OPCs before maturation [37]. However, as observed here, the poly-ornithine-laminin coated adherent plates is insufficient to prevent the differentiation of the PDGFRa + hOPCs.

The use of HUVECs as endothelial partners in co-culture is justified since HUVECs in pre-clinical trials have improved myelination in murine models of amyotrophic lateral sclerosis [42]. Comparative expression profiles of HUVECs and human cerebral endothelial cells show relatively more IL6 being expressed by cerebral endothelial cells than HUVECs [43]. Observations of the present study show IL6 transcripts to more abundant in HUVECs relative to OPCs, making IL6 the one of the more prevalent endothelial cell-derived factors. Hence IL6 could contribute to some of the observed co-culture effects. It has recently been shown that inhibition of IL 6 downstream signaling by Janus kinase inhibitor tofacitinib can improve myelination outcome [44], indicating that IL6 signaling is unfavorable for remyelination strategies. Brain endothelial cells are also an integral component of the tumorigenic niche of astrocytic tumors [45] where vasculature is critical in balancing the proliferation through mTOR signaling [46] and with Akt-MAPK signaling sensitizes inhibition and differentiation [47].

Mouse endothelial progenitor cell secretome improves cognitive function in mouse models of cerebral hypoperfusion. This secretome is enriched with 38 proteins, including angiogenin, endothelin 1, PDGF AA, PDGF-AB, PDGF-BB, FGF1, FGF2, but the list does not include the BMPs, or any other TGF $\beta$ receptor inducers [48]. Likewise, in the present study, endothelin1 was detected as the second most prevalent out of the transcripts of soluble factors assayed for in the HUVECs. The effect of endothelin 1 on proliferation of PDGFRa + hOPCs was followed using specific inhibitors to EDNRA (BQ 123, Sigma, USA) and EDNRB (BQ 788, Sigma, USA). It has been observed that daily treatment with $10 \mathrm{nM}$ of BQ 788, could inhibit the endothelial mediated PDGFRa + hOPC sphere formation, and ${ }^{3} \mathrm{H}$ - thymidine incorporation in hOPC spheres but not with BQ 123 (10-1000nM), signifying specificity of endothelial derived EDN1 action in the PDGFRa + hOPCs through EDNRB, confirming the expression data for EDNRB in these cells (Table 1). These observations are also supported by the reports of EDN1 signaling maintaining proliferation of NG2 + murine OPCs that are also Olig2 + and PDGFRa+ [49-51]. The key regulator of differentiation of PDGFRa + hOPCs is however BMP signaling which induces the differentiation of hOPCs towards astrocytes in agreement with previous studies with murine OPCs [36-38]. Hence the role of BMPs in remyelination therapy needs to be discussed in this context.

Bone morphogenic proteins induce differentiation by reducing proliferation in NSCs [40]. Due to this ability to induce differentiation, BMPs are useful in cancer remission [52]. BMPs also induce stem cell renewal by the Smad, PI3K/Akt, and Wnt-dependent signaling [53]. Thus, BMPs induce both proliferation and differentiation. Early OPCs expressing A2B5 overexpress BMP inhibitors as neuralin and BMP-activin 
membrane-bound inhibitor in tonic defense against BMP signaling [54]. However, such tonic defense against BMP signaling seems insufficient in PDGFRa + human OPCs to prevent their astrocytic differentiation in presence of the excess of BMPs presented by the human endothelial cells. BMP4 mediated inhibition of OPC differentiation involves ID and Olig proteins $[55,56]$, and is stage-specific with mature oligodendrocytes failing to respond to BMP2 and BMP4 [57-60]. Bone morphogenic proteins and their receptors are upregulated in most human white matter diseases, and directly correlate with the inflammatory activity in multiple sclerosis lesions [61]. BMP are well-known inhibitors of myelination and re-myelination processes [62]. Noggin inhibits BMP4 signaling to promote OPC maturation as well as myelination [63]. Pharmacological inhibitors of BMP as LDN-19318 or selective deletion of BMP receptor type IA (BMPRIA) also have similar effects [63]. Thus, remyelination therapies should be directed towards reducing the BMP levels. BMP4 also accelerates the commitment of hESCs to endothelial lineage [64] indicating of possible positive feedforward loop between the two cell types; not explored in this study.

Multiple sclerosis lesions from post mortem tissues show skewed cellular heterogeneity in terms of reduced numbers of early and intermediate OPCs, while the more mature oligodendrocytes show increased expression of many myelin proteins indicating a change in their transcriptional profile to match the disease contingency [65]. Oligodendrocytes are now understood to be active immunomodulators in chronic inflammatory demyelinating diseases as multiple sclerosis. The Mouse PDGFRa + OPCs in experimental autoimmune encephalomyelitis are capable of phagocytosis of fluorescence beads as well as myelin. Disease-specific oligodendroglia in human multiple sclerosis brains co-express Olig1 and MHC-II demonstrating a significantly different transcriptional profile that reflects the disease context [66]. Also, the skewed cellular heterogeneity observed in multiple sclerosis lesions extends to astrocytes and endothelial cells, with both these cell types seen in relatively increased proportions in the MS lesions than in controls [65] making the outcome of human endothelial and PDGFRa + hOPCs described in this study relevant to addressing an effective regenerative therapy against multiple sclerosis and other demyelinating diseases.

The role of astrocytes in such disease context depends on the status of the astrocytes [18]. However, during development astrocytes favor the maturation, migration and myelination stages of oligodendrocyte precursors through secreted factors as PDGF, sonic hedgehog (Shh), and BDNF respectively $[67,68]$. Apart from this, astrocyte expressed CNTF and LIF help with the progress of myelination while the chemokine CXCL1 is deleterious for OPC maturation and migration $[67,69]$. However, reactive astrocytes release remyelination inhibitory factors as ECM including chondroitin sulphate, proteoglycans (CSPGs), hyaluronan, tenascin-C, and fibronectin, all of which are present in MS lesions [18]. Apart from this, reactive astrocytes also release endothein 1 , also determined to be abundant in this study in endothelial cells. Though endothelin 1 encourages proliferation of murine NG2 + OPCs [49-51] and PDGFRa + hOPCs, endothelin1 induced Jagged expression in reactive astrocytes is known to cause Notch activation in the OPCs leading to inhibition of OPC differentiation, thereby making endothelin 1, an endogenous inhibitor of remyelination, and a target for remyelination therapy [70]. Apart from this, both the neurotoxic C3D expressing astrocyte and the protective S100a10 + astrocytes express BMP4 in lesions from MS patients, indicating their involvement in inflammation and inhibition of 
remyelination [71, 72]. Thus, depending on their naïve or reactive status, astrocytes either positively or adversely affect the remyelination therapy making the results of this study relevant in designing of transplantation therapy using PDGFRa + hOPCs.

\section{Conclusion}

Overall, this study provides support to the inference that, endothelial cells in trans-well co-culture induce proliferation of PDGFRa + hOPCs and their BMP mediated astrocytic differentiation, as evidenced by attenuation of astrocytic differentiation by noggin. The novel aspect of the study is that it is the first report of co-culture interaction of a human derived endothelial cell with an oligodendrocyte precursor of human origin. The study thus strengthens the conclusions previously drawn using both or at least one of the co-culture partner cells from murine origin. The study demonstrates the bi-potential nature of the PDGFRa + hOPCs with differentiation capability towards both oligodendrocytes as well as astrocytes. It also shows the vulnerability of the PDGFRa + hOPCs to BMPs and has implications in designing of remyelination therapy. Since noggin can overcome the bone morphogenic protein induced astrocytic differentiation of PDGFRa + hOPCs, these cells may be better used in combination with the pharmacological inhibitors of bone morphogenic proteins towards improving their efficacy in remyelination therapy.

\section{Abbreviations}

\section{PDGFRa+}

platelet derived growth factor receptor alpha positive

CD140a

cluster differentiation 140 a

OPCs

oligodendrocyte progenitor cells

HUVECS

human umbilical vein endothelial cells

hOPCs

human oligodendrocyte progenitor cells

BMPs

bone morphogenic proteins, EDN1:endothelin1, GAS6:growth arrest specific 6, IL6:interleukin 6

PTN

pleiotrophin, FGF9:fibroblast growth factor 9, CNTF:ciliary neurotrophic factor

LIF

leukemia inhibitory factor

NSCs

neural stem cells

CD9 
cluster differentiation 9

gw

gestational weeks

DNase, DMEM

Dulbecco's Minimal Essential Medium

FGF2

fibroblast growth factor 2, PD-FBS:platelet depleted fetal bovine serum. EDTA:ethylene diamine tetra acetic acid

PDGF-AA

platelet derived growth factor alpha

GFAP

glial fibrillary acidic protein.

\section{Declarations}

\section{Funding}

No specific funds were received for performing this study. The study was supported by the funds available to Centre for Translational Neuromedicine. The author acknowledges University of Rochester for the Postdoctoral Fellowship from the Neurology Fellowship Program.

\section{Competing interests}

The author has no relevant competing financial or non-financial interests to disclose related to this work.

\section{Author's Contributions}

Asmita Dasgupta: Conception and design, Collection and assembly of data, Data analysis and interpretation, Manuscript writing, and final approval of the manuscript.

\section{Data Availability Statement}

All data generated or analyzed during this study are included in this published article and its supplementary information files.

\section{Ethics approval}

All experimental protocols were approved by the University of Rochester, Research Subjects Review Board vide IRB/RSRB approval \# 26905 for isolation of OPCs and performed using deidentified aborted fetal brain tissue, obtained from surgical pathology that were considered exempt by IRB/RSRB.

\section{Consent to participate}

Deidentified tissues from surgical pathology considered exempt. 


\section{Consent for publish}

Not applicable.

\section{Employment}

This work was done by the author during her tenure as a Postdoctoral Research Associate at the Centre for Translational Neuromedicine, University of Rochester Medical Centre, Rochester, New York, USA. The author is presently an Assistant Professor at the Department of Biochemistry and Molecular Biology, School of Life Sciences, Pondicherry University, Pondicherry 605014, India.

\section{Acknowledgments}

The author thanks the University of Rochester for the postdoctoral fellowship from the Neurology Fellowship Program for investigative training in Clinical Neuroscience in Cell and Gene Therapy at the Centre of Translational Neuromedicine. The author is also grateful to the Centre of Translational Neuromedicine for making available funds to support this work.

\section{References}

1. Shen Q, Wang Y, Kokovay E et al (2008) Adult SVZ stem cells lie in a vascular niche: a quantitative analysis of niche cell-cell interactions. Cell Stem Cell 3:289300. https://doi.org/10.1016/j.stem.2008.07.026

2. Tavazoie M, Van der Veken L, Silva-Vargas V et al (2008) A specialized vascular niche for adult stem cells. Cell Stem Cell 3:279-288. https://doi.org/10.1016/j.stem.2008.07.025

3. Leventhal C, Rafii S, Rafii D et al (1999) Endothelial trophic support of neuronal production and recruitment from the adult mammalian subependyma. Mol Cell Neurosci 13:450-464. https://doi.org/10.1006/mcne.1999.0762.

4. Kempermann G, Song HJ, \& Gage, FH (2015) Neurogenesis in the adult hippocampus. Cold Spring Harb Perspect Biol 7(9): a018812. https://doi.org/10.1101/cshperspect.a018812.

5. Shen Q, Goderie SK, Jin L et al (2004) Endothelial cells stimulate self-renewal and expand neurogenesis of neural stem cells. Science 304:1338-4. https://doi.org/10.1126/science.1095505.

6. Lim DA, Alvarez-Buylla A (2016) The Adult Ventricular-Subventricular Zone (V-SVZ) and Olfactory Bulb (OB) Neurogenesis. Cold Spring Harb Perspect Biol 8(5). https://doi.org/10.1101/cshperspect.a018820.

7. Tsai HH, Niu J, Munji R et al (2016) Oligodendrocyte precursors migrate along vasculature in the developing nervous system. Science 351: 379-384. https://doi.org/10.1126/science.aad3839.

8. Zhang Y, Sloan SA, Clarke LE et al (2016) Purification and Characterization of Progenitor and Mature Human Astrocytes Reveals Transcriptional and Functional Differences with Mouse. Neuron 89: 3753. https://doi.org/10.1016/j.neuron.2015.11.013. 
9. Goldman SA, Kuypers NJ (2015) How to make an oligodendrocyte. Development 142: 3983-3995. https://doi.org/10.1242/dev.126409.

10. Suzuki N, Sekimoto K, Hayashi C et al (2017) Differentiation of Oligodendrocyte Precursor Cells from Sox10-Venus Mice to Oligodendrocytes and Astrocytes. Scientific Reports 7(1): 14133. https://doi.org/10.1038/s41598-017-14207-0.

11. Petersen MA, Ryu JK, Chang KJ et al (2017) Fibrinogen Activates BMP Signaling in Oligodendrocyte Progenitor Cells and Inhibits Remyelination after Vascular Damage. Neuron 96(5): 10031012. https://doi.org/10.1016/j.neuron.2017.10.008.

12. Dincman TA, Beare JE, Ohri SS et al (2012) Isolation of cortical mouse oligodendrocyte precursor cells. J Neurosci Methods 209(1): 219-26. https://doi.org/10.1016/j.jneumeth.2012.06.017.

13. Roy NS, Wang S, Harrison-Restelli C et al (1999) Identification, isolation, and promoter-defined separation of mitotic oligodendrocyte progenitor cells from the adult human subcortical white matter. J Neurosci 19: 9986-9995. https://doi.org/10.1523/JNEUROSCI.19-22-09986.

14. Windrem MS, Nunes MC, Rashbaum WK et al (2004) Fetal and adult human oligodendrocyte progenitor cell isolates myelinate the congenitally dysmyelinated brain. Nature Medicine 10: 93-97. https://doi.org/10.1038/nm974.

15. Xu L, Ryu J, Hiel H, Menon A, et al (2015) Transplantation of human oligodendrocyte progenitor cells in an animal model of diffuse traumatic axonal injury: survival and differentiation. Stem Cell Res Ther 6(1): 93. https://doi.org/10.1186/s13287-015-0087-0.

16. Kuhn S, Gritti L, Crooks D, et al (2019) Oligodendrocytes in Development, Myelin Generation and Beyond. Cells 8(11): 1424-1447. https://doi.org/10.3390/cells8111424.

17. Sim FJ, McClain CR, Schanz SJ et al (2011) CD140a identifies a population of highly myelinogenic, migration-competent and efficiently engrafting human oligodendrocyte progenitor cells. Nature Biotechnology 29: 934 -941. https://doi.org/10.1038/nbt.1972.

18. Rawji KS, Gonzalez Martinez GA, Sharma A, Franklin RJM (2020) The Role of Astrocytes in Remyelination. Trends Neurosci 43(8): 596-607. https://doi.org/10.1016/j.tins.2020.05.006.

19. Wang Y, Cheng X, He Q et al (2011) Astrocytes from the contused spinal cord inhibit oligodendrocyte differentiation of adult oligodendrocyte precursor cells by increasing the expression of bone morphogenetic proteins. J Neurosci 31(16): 6053-8. https://doi.org/ 10.1523/JNEUROSCI.552409.2011.

20. Rodchenkov I, Babur O, Luna A et al (2020) Pathway Commons 2019 Update: integration, analysis and exploration of pathway data. Nucleic Acids Research 48(D1): D489-D497. https://doi.org/10.1093/nar/gkz946.

21. Cerami EG, Gross BE, Demir E et al (2010) Pathway Commons, a web resource for biological pathway data. Nucleic Acids Research 39: D685-D690. https://doi.org/10.1093/nar/gkq1039.

22. Demir E, Cary MP, Paley S et al (2010) BioPAX - A community standard for pathway data sharing. Nature Biotechnology 28: 935-942. https://doi.org/10.1038/nbt.1666. 
23. Shannon P, Markiel A, Ozier $O$ et al (2003) Cytoscape: a software environment for integrated models of biomolecular interaction networks. Genome Research 13: 2498-2504. https://doi.org/10.1101/gr.1239303.

24. Ozawa T, Brennan CW, Wang $L$ et al (2010) PDGFRA gene rearrangements are frequent genetic events in PDGFRA-amplified glioblastomas. Genes Dev 24: 2205-2218. https://doi.org/ 10.1101/gad.1972310.

25. Verhaak RG, Hoadley KA, Purdom E et al (2010) Integrated genomic analysis identifies clinically relevant subtypes of glioblastoma characterized by abnormalities in PDGFRA, IDH1, EGFR, and NF1. Cancer Cell 17, 98-110. https://doi.org/10.1016/j.ccr.2009.12.020.

26. Jackson EL, Garcia-Verdugo JM, Gil-Perotin S et al (2006) PDGFRa positive B cells are neural stem cells in the adult SVZ that form glioma-like growths in response to increased PDGF signaling. Neuron 51: 187-199. https://doi.org/10.1016/j.neuron.2006.06.012.

27. Huang Y, Hoffman C, Rajappa P et al (2014) Oligodendrocyte progenitor cells promote neovascularization in glioma by disrupting the blood-brain barrier. Cancer Research 74: 1011-1021. https://doi.org/ 10.1158/0008-5472.CAN-13-1072.

28. Marques S, Zeisel A, Codeluppi S, van Bruggen D, Mendanha Falcão A et al (2016) Oligodendrocyte heterogeneity in the mouse juvenile and adult central nervous system. Science 352(6291), 13261329. https://doi.org/10.1126/science.aaf6463.

29. Marques S, van Bruggen D, Vanichkina DP, Floriddia EM, Munguba $\mathrm{H}$ et al (2018) Transcriptional Convergence of Oligodendrocyte Lineage Progenitors during Development. Dev Cell 46(4): 504-517, e7. https://doi.org/10.1016/j.devcel.2018.07.005.

30. Yao Y, Chen ZL, Norris EH, Strickland S (2014) Astrocytic laminin regulates pericyte differentiation and maintains blood brain barrier integrity. Nature Communications 5: 3413. https://doi.org/10.1038/ncomms4413.

31. Marisca R, Hoche T, Agirre E, Hoodless LJ, Barkey W et al (2020) Functionally distinct subgroups of oligodendrocyte precursor cells integrate neural activity and execute myelin formation. Nature Neuroscience 23(3): 363-374. https://doi.org/ 10.1038/s41593-019-0581-2.

32. Cui QL, D'Abate L, Fang J et al (2012) Human fetal oligodendrocyte progenitor cells from different gestational stages exhibit substantially different potential to myelinate. Stem Cells Dev 21: 18311837. https://doi.org/10.1089/scd.2011.0494.

33. Mela A, Goldman JE (2009) The tetraspanin KAl1/CD82 is expressed by late-lineage oligodendrocyte precursors and may function to restrict precursor migration and promote oligodendrocyte differentiation and myelination. J Neurosci 29(36): 11172-81. https://doi.org/10.1523/JNEUROSCI.3075-09.2009.

34. Terada N, Baracskay K, Kinter M et al (2002) The tetraspanin protein, CD9, is expressed by progenitor cells committed to oligodendrogenesis and is linked to beta1 integrin, CD81, and Tspan-2. Glia 40: 350-359. https://doi.org/10.1002/glia.10134. 
35. Raff MC, Miller RH, Noble M (1983). A glial progenitor that develops in vitro into an astrocyte or an oligodendrocyte depending on culture medium. Nature 303: 390-396. https://doi.org/10.1038/303390a0.

36. Imura T, Tane K, Toyoda $\mathrm{N}$ et al (2008) Endothelial cell-derived bone morphogenetic proteins regulate glial differentiation of cortical progenitors. Eur J Neurosci 27: 1596-1606. https://doi.org/ 10.1111/j.1460-9568.2008.06134.x.

37. Arai K, Lo EH (2009) An oligovascular niche: cerebral endothelial cells promote the survival and proliferation of oligodendrocyte precursor cells. J Neurosci 29: 4351-4355. https://doi.org/10.1523/JNEUROSCI.0035-09.2009.

38. Mi H, Haeberle H, Barres BA (2001) Induction of astrocyte differentiation by endothelial cells. J Neurosci 21:1538-1547. https://doi.org/10.1523/JNEUROSCI.21-05-01538.2001.

39. Mathieu C, Fouchet P, Gauthier LR et al (2006) Co-culture with endothelial cells reduces the population of cycling LeX neural precursors but increases that of quiescent cells with a side population phenotype. Exp. Cell Res 312: 707-718. https://doi.org/10.1016/j.yexcr.2005.11.018.

40. Mathieu C, Sii-Felice K, Fouchet P et al (2008) Endothelial cell-derived bone morphogenetic proteins control proliferation of neural stem/progenitor cells. Mol Cell Neurosci 38: 569-577. https://doi.org/10.1016/j.mcn.2008.05.005.

41. Mabie PC, Mehler MF, Kessler JA (1999). Multiple roles of bone morphogenetic protein signaling in the regulation of cortical cell number and phenotype. J Neurosci 19: 7077-7088. https://doi.org/10.1523/JNEUROSCI.19-16-07077.1999.

42. Garbuzova-Davis S, Rodrigues MC, Mirtyl S et al (2012) Multiple intravenous administrations of human umbilical cord blood cells benefit in a mouse model of ALS. PLoS One 7(2): e31254. https://doi.org/10.1371/journal.pone.0031254.

43. Kallmann BA, Wagner $S$, Hummel $V$ et al (2002) Characteristic gene expression profile of primary human cerebral endothelial cells. FASEB J 16: 589-91. https://doi.org/10.1096/fj.01-0594fje.

44. Günaydın C, Önger ME, Avcı B, Bozkurt A, Terzi M, Bilge SS (2021) Tofacitinib enhances remyelination and improves myelin integrity in cuprizone-induced mice. Immunopharmacol Immunotoxicol 43(6): 790-798. https://doi.org/10.1080/08923973.2021.1986063.

45. Gilbertson RJ, Rich JN (2007) Making a tumour's bed: glioblastoma stem cells and the vascular niche. Nature Reviews Cancer 7(10): 733-736. https://doi.org/10.1038/nrc2246.

46. Galan-Moya EM, Le Guelte A, Lima Fernandes E et al (2011) Secreted factors from brain endothelial cells maintain glioblastoma stem-like cell expansion through the mTOR pathway. EMBO Rep 12 (5): 470-476. https://doi.org/10.1038/embor.2011.39.

47. Eyler CE, Foo WC, LaFiura KM et al (2008) Brain cancer stem cells display preferential sensitivity to Akt inhibition. STEM CELLS, 26(12), 3027-3036. https://doi.org/10.1634/stemcells.2007-1073.

48. Maki T, Morancho A, Martinez-San Segundo P, Hayakawa K, Takase H, et al (2018) Endothelial Progenitor Cell Secretome and Oligovascular Repair in a Mouse Model of Prolonged Cerebral Hypoperfusion. Stroke 49(4):1003-1010. https://doi.org/10.1161/STROKEAHA.117.019346. 
49. Gadea A, Aguirre A, Haydar TF et al (2009) Endothelin-1 regulates oligodendrocyte development. J. Neurosci., 29, 10047-10062. https://doi.org/10.1523/JNEUROSCI.0822-09.2009.

50. Adams KL, Riparini G, Banerjee P et al (2020) Endothelin-1 signaling maintains glial progenitor proliferation in the postnatal subventricular zone. Nature Communications 11: 2138. https://doi.org/10.1038/s41467-020-16028-8.

51. Adams KL, Dahl KD, Gallo V, Macklin WB (2021) Intrinsic and extrinsic regulators of oligodendrocyte progenitor proliferation and differentiation. Semin Cell Dev Biol 116: 16-24. https://doi.org/10.1016/j.semcdb.2020.10.002.

52. Piccirillo SG, Reynolds BA, Zanetti N, et al (2006) Bone morphogenetic proteins inhibit the tumorigenic potential of human brain tumor-initiating cells. Nature 444: 761-765. https://doi.org/10.1038/nature05349.

53. Lee MY, Lim HW, Lee SH, Han HJ (2009) Smad, PI3K/Akt, and Wnt-dependent signaling pathways are involved in BMP-4-induced ESC self-renewal. STEM CELLS 27:1858-1868. https://doi.org/10.1002/stem.124.

54. Sim FJ, Lang JK, Waldau B et al (2006) Complementary patterns of gene expression by human oligodendrocyte progenitors and their environment predict determinants of progenitor maintenance and differentiation. Ann Neurol 59: 763-779. https://doi.org/10.1002/ana.20812.

55. Samanta J, Kessler JA (2004) Interactions between ID and OLIG proteins mediate the inhibitory effects of BMP4 on oligodendroglial differentiation. Development 131: 4131-4142. https://doi.org/10.1242/dev.01273.

56. Cheng $X$, Wang $Y, H e Q$ et al (2007) Bone morphogenetic protein signaling and olig1/2 interact to regulate the differentiation and maturation of adult oligodendrocyte precursor cells. STEM CELLS 25: 3204-3214. https://doi.org/10.1634/stemcells.2007-0284.

57. Grinspan JB, Edell E, Carpio DF et al (2000) Stage-specific effects of bone morphogenetic proteins on the oligodendrocyte lineage. J Neurobiol 43: 1-17. PMID: 10756062.

58. Grinspan JB (2015) Bone Morphogenetic Proteins: Inhibitors of Myelination in Development and Disease. Vitam Horm 99:195-222. https://doi.org/10.1016/bs.vh.2015.05.005.

59. Wheeler NA, Fuss B (2016) Extracellular cues influencing oligodendrocyte differentiation and (re)myelination. Experimental Neurology 283(Pt B): 512-530. https://doi.org/10.1016/j.expneurol.2016.03.019.

60. Tiane A, Schepers M, Rombaut B et al (2019) From OPC to Oligodendrocyte: An Epigenetic Journey. Cells 8(10): 1236-1251. https://doi.org/10.3390/cells8101236.

61. Costa C, Eixarch H, Martínez-Sáez E et al (2019) Expression of Bone Morphogenetic Proteins in Multiple Sclerosis Lesions. Am J Pathol 189(3): 665-676. https://doi.org/10.1016/j.ajpath.2018.11.007.

62. Grinspan JB (2020) Inhibitors of Myelination and Remyelination, Bone Morphogenetic Proteins are Upregulated in Human Neurological Disease. Neurochem Res 45(3): 656-662. https://doi.org/10.1007/s11064-020-02980-w. 
63. Govier-Cole AE, Wood RJ, Fletcher JL et al (2019) Inhibiting Bone Morphogenetic Protein 4 Type I Receptor Signaling Promotes Remyelination by Potentiating Oligodendrocyte Differentiation. eNeuro, 6(2), 0399-0418. https://doi.org/10.1523/ENEURO.0399-18.2019.

64. Goldman O, Feraud O, Boyer-Di Ponio J et al (2009) A boost of BMP4 accelerates the commitment of human embryonic stem cells to the endothelial lineage. STEM CELLS 27: 1750-1759. https://doi.org/ 10.1002/stem.100.

65. Jäkel S, Agirre E, Mendanha Falcão A, van Bruggen, D., Lee, K.W., Knuesel, I., et al. (2019). Altered human oligodendrocyte heterogeneity in multiple sclerosis. Nature, 566(7745), 543-547. https://doi.org/10.1038/s41586-019-0903-2.

66. Falcão AM, van Bruggen D, Marques S, Meijer M, Jäkel S et al (2018) Disease-specific oligodendrocyte lineage cells arise in multiple sclerosis. Nature Medicine 24(12): 1837-1844. https://doi.org/10.1038/s41591-018-0236-y.

67. Traiffort E, Kassoussi A, Zahaf A et al (2020) Astrocytes and Microglia as Major Players of Myelin Production in Normal and Pathological Conditions. Front Cell Neurosci 14:79. https://doi.org/10.3389/fncel.2020.00079.

68. Ortega MC, Cases O, Merchán P et al (2012) Megalin mediates the influence of sonic hedgehog on oligodendrocyte precursor cell migration and proliferation during development. Glia 60(6): 851-66. https://doi.org/10.1002/glia.22316.

69. Tsai HH, Frost E, To V, Robinson S, Ffrench-Constant C et al (2002) The chemokine receptor CXCR2 controls positioning of oligodendrocyte precursors in developing spinal cord by arresting their migration. Cell 110(3): 373-83. https://doi.org/10.1016/s0092-8674(02)00838-3.

70. Hammond TR, Gadea A, Dupree J, Kerninon C, Nait-Oumesmar B, Aguirre A, Gallo V (2014) Astrocytederived endothelin-1 inhibits remyelination through notch activation. Neuron 81(3): 588-602. https://doi.org/10.1016/j.neuron.2013.11.015.

71. Grinspan JB (2020) Inhibitors of Myelination and Remyelination, Bone Morphogenetic Proteins, are Upregulated in Human Neurological Disease. Neurochem Res 45(3): 656-662. https://doi.org/10.1007/s11064-020-02980-w.

72. Harnisch K, Teuber-Hanselmann S, Macha N et al (2019) Myelination in Multiple Sclerosis Lesions Is Associated with Regulation of Bone Morphogenetic Protein 4 and Its Antagonist Noggin. Int $\mathrm{J} \mathrm{Mol}$ Sci 20(1): 154. https://doi.org/10.3390/ijms20010154.

\section{Figures}




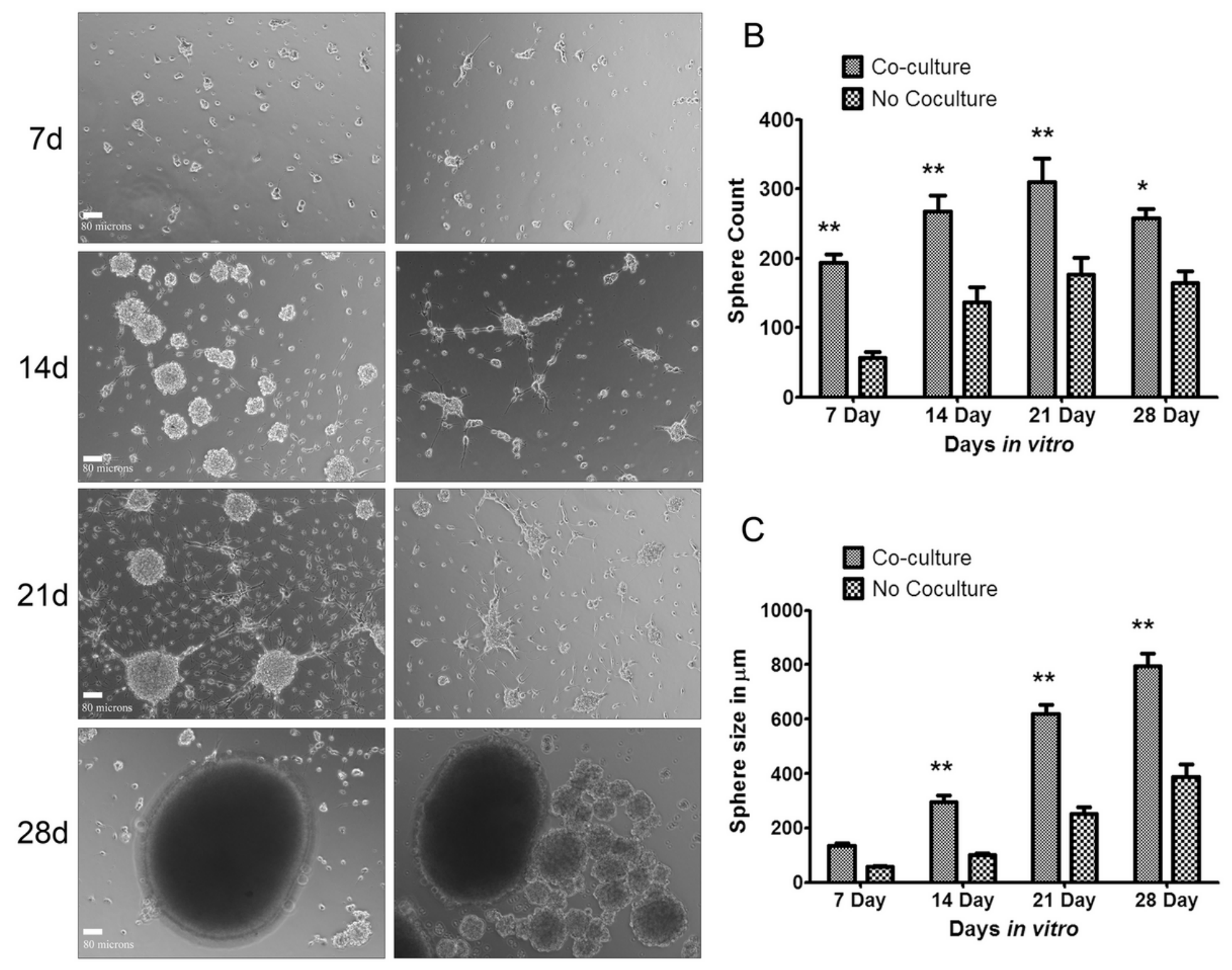

Figure 1

Co-culture with HUVECs stimulates sphere formation in PDGFRa+ hOPCs in a time-dependent manner (A) Representative micrographs of spheres formed by PDGFRa+ hOPCs from a 22gw specimen in proliferative condition at 7, 14, 21, and 28 days, with or without HUVEC co-culture. Scale bar, $80 \mu \mathrm{m}$. (B) The number of spheres were counted at each time point. Average number of spheres formed are plotted as mean \pm SE against time at $7,14,21$, and 28 days from $n=3$ independent experiments with biological replicates. Each biological replicate was seeded in quadruplicate wells each for both with as well as without HUVEC co-culture. (C) The PDGFRa+ hOPCs sphere diameters were also measured with graduated grid on microscope eyepiece. Average size of the largest hOPC sphere in each well are plotted as mean \pm SE against time at 7, 14, 21, and 28 days from $n=3$ independent experiments (biological replicates) each with quadruplicate wells for with or without HUVEC co-culture. Two-way repeated measures ANOVA, followed by Bonferroni's correction of p-values was used to determine significance of 
difference between and across groups. Post hoc $p$-values are designated as * for $p<0.05$ and ** for $p<0.01$.

\section{Figure 2}

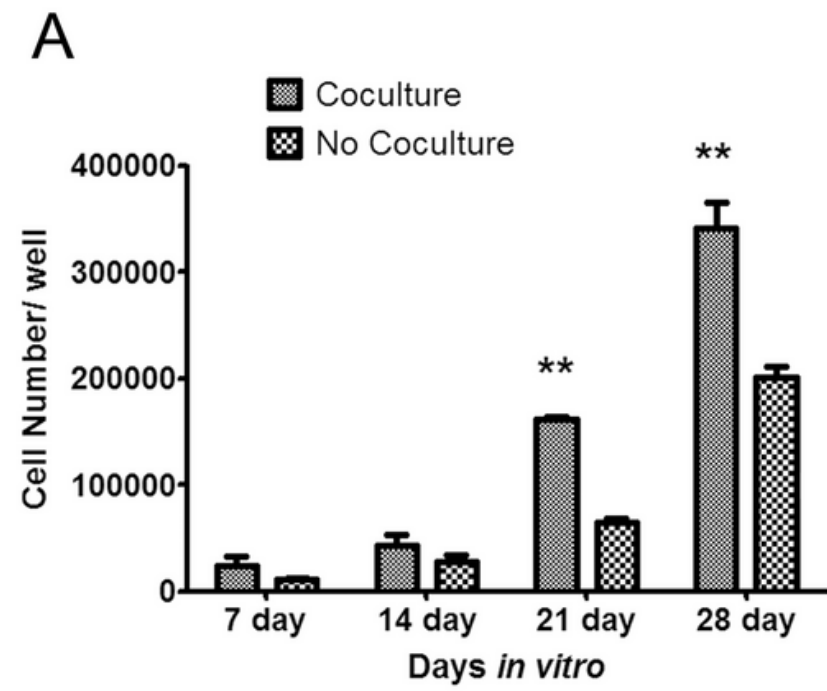

\section{B}

Coculture

$\otimes$ No Coculture

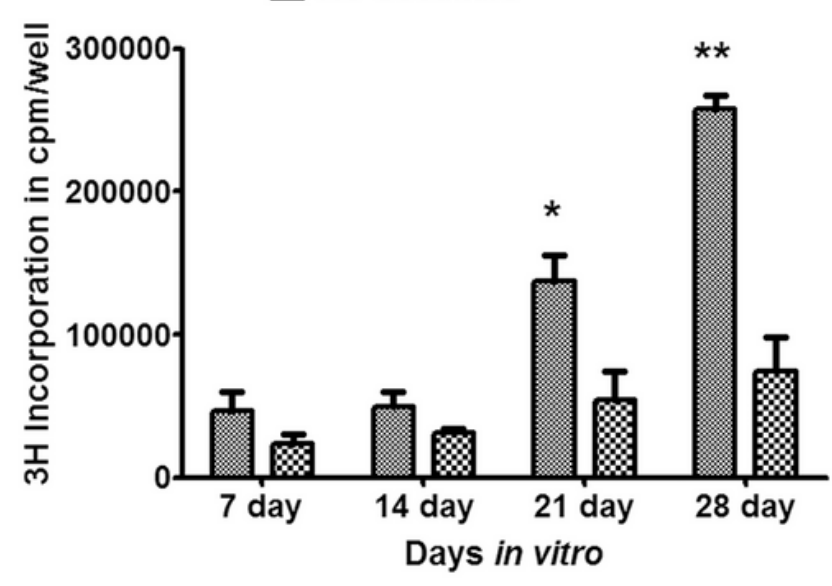

C

$$
\text { Ð }
$$

Co-culture
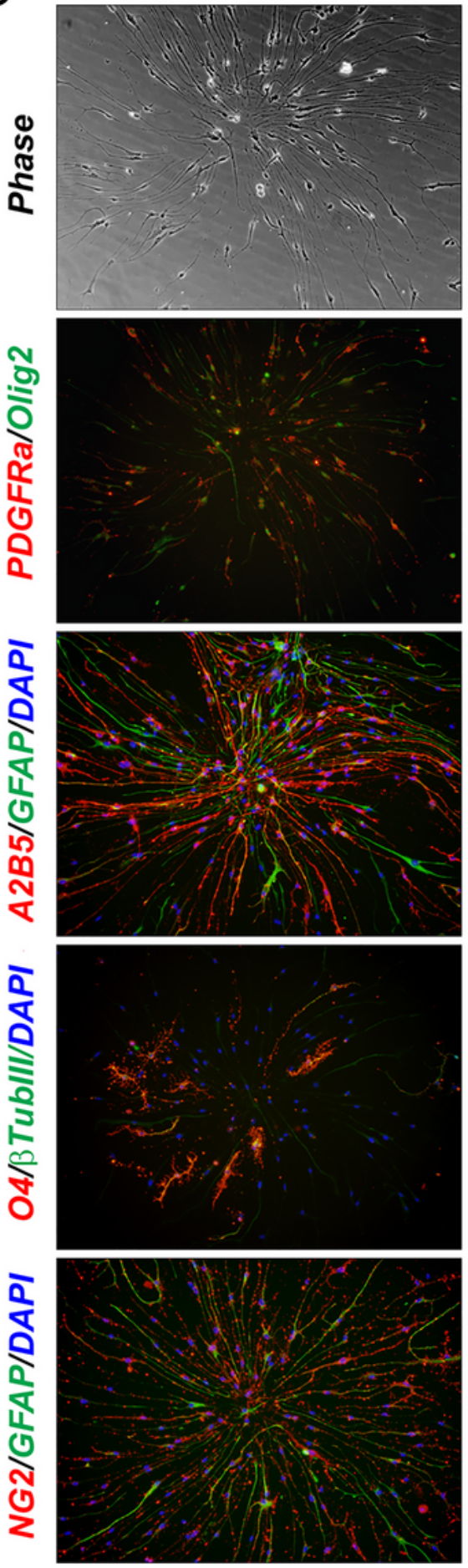

No co-culture
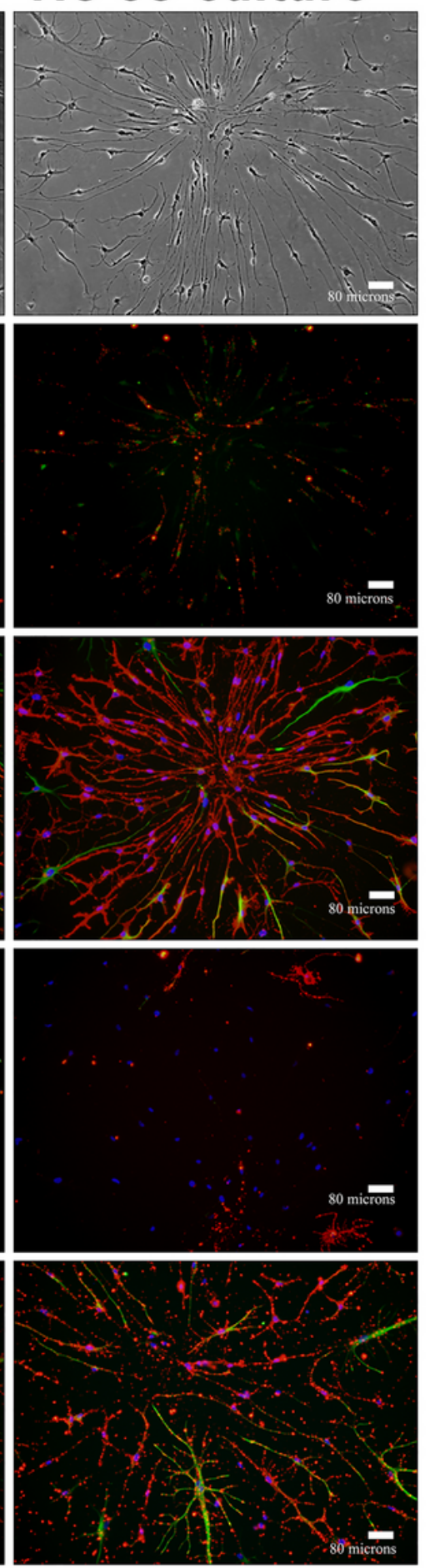

Figure 2

Co-culture with HUVECs induces proliferation of PDGFRa+ hOPCs to form spheres but not their differentiation outcome (A) The average number of cell count from dissociated PDGFRa+ hOPC spheres are plotted as mean $\pm S E$ at $7,14,21$, and 28 days from $n=3$ independent experiments (biological 
replicates), each with quadruplicate wells for with or without HUVEC co-culture. (B) Average cumulative [3H methyl] -Thymidine incorporation measured as mean $\pm \mathrm{SE} \mathrm{cpm} /$ well are plotted against time at 7 , 14,21 , and 28 days from $n=3$ independent assays (biological replicates) in replicate quadruplicate wells for with or without HUVEC co-culture conducted in parallel to the sphere dissociation assay. Two-way repeated measures ANOVA, followed by Bonferroni's correction of $p$-values was used to determine significance of difference between and across groups Post hoc $p$ values are designated as * for $p<0.05$ and $* \star$ for $p<0.01$. (C) Representative images of differentiated hOPC spheres from with and without coculture at 14 days in vitro from a $20.6 \mathrm{gw}$ specimen. The OPC spheres re-plated in differentiation condition after 14 days were allowed to differentiate on poly ornithine - laminin. Immunocytochemistry was performed for PDGFRa/Olig2, A2B5/GFAP, 04/beta III tubulin, NG2/GFAP revealed the pattern of expression to be similar for spheres grown with or without co-culture. The nuclear stain is DAPI. Scale bar, $80 \mu \mathrm{m}$.

A

Fluorescence
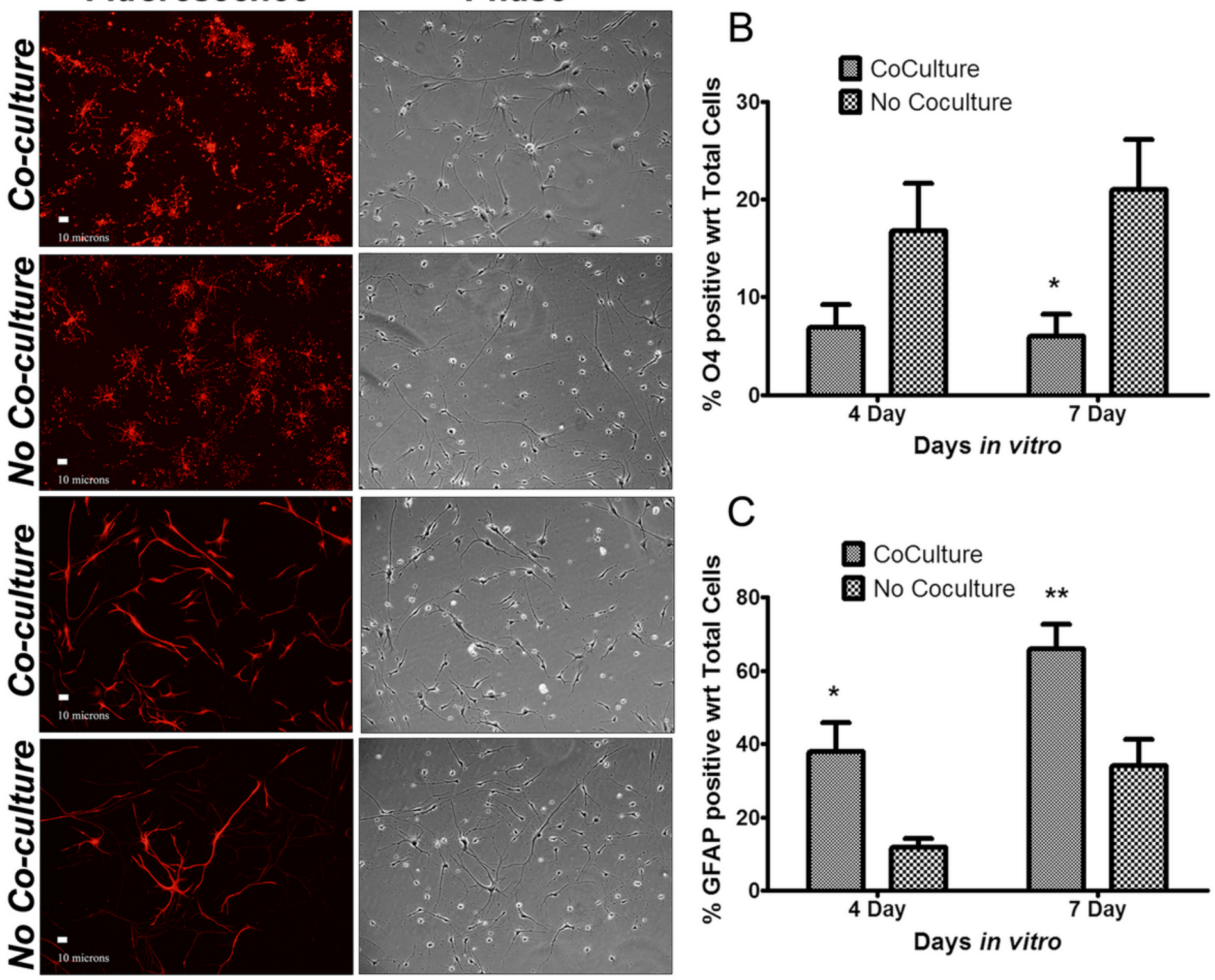


\section{Figure 3}

Co-culture with HUVECs induces astrocytic differentiation in the PDGFRa+ hOPCs (A) Representative micrographs of PDGFRa+ hOPCs differentiated on poly-ornithine laminin substrate, with or without HUVEC co-culture, in the presence of $25 \mathrm{ng} / \mathrm{ml}$ of VEGF in serum-free media (20 gw specimen), immunostained for $\mathrm{O} 4$ and GFAP,. Scale bar, 10 $\mu \mathrm{m}$. (B) Percent of $\mathrm{O} 4$ positive and (C) Percent of GFAP positive cells out of total cells counted in phase in ten random fields or 200 cells/well as mean \pm SE of counts culture plotted against number of days, from $n=5$ independent experiments (biological replicates), each with triplicate wells for with or without HUVEC co-culture. Two-way Repeated Measures ANOVA, followed by Bonferroni's correction of $p$-values was used to determine significance of difference between and across groups. Post hoc $p$ values are designated as * for $p<0.05$ and $* *$ for $p<0.01$.

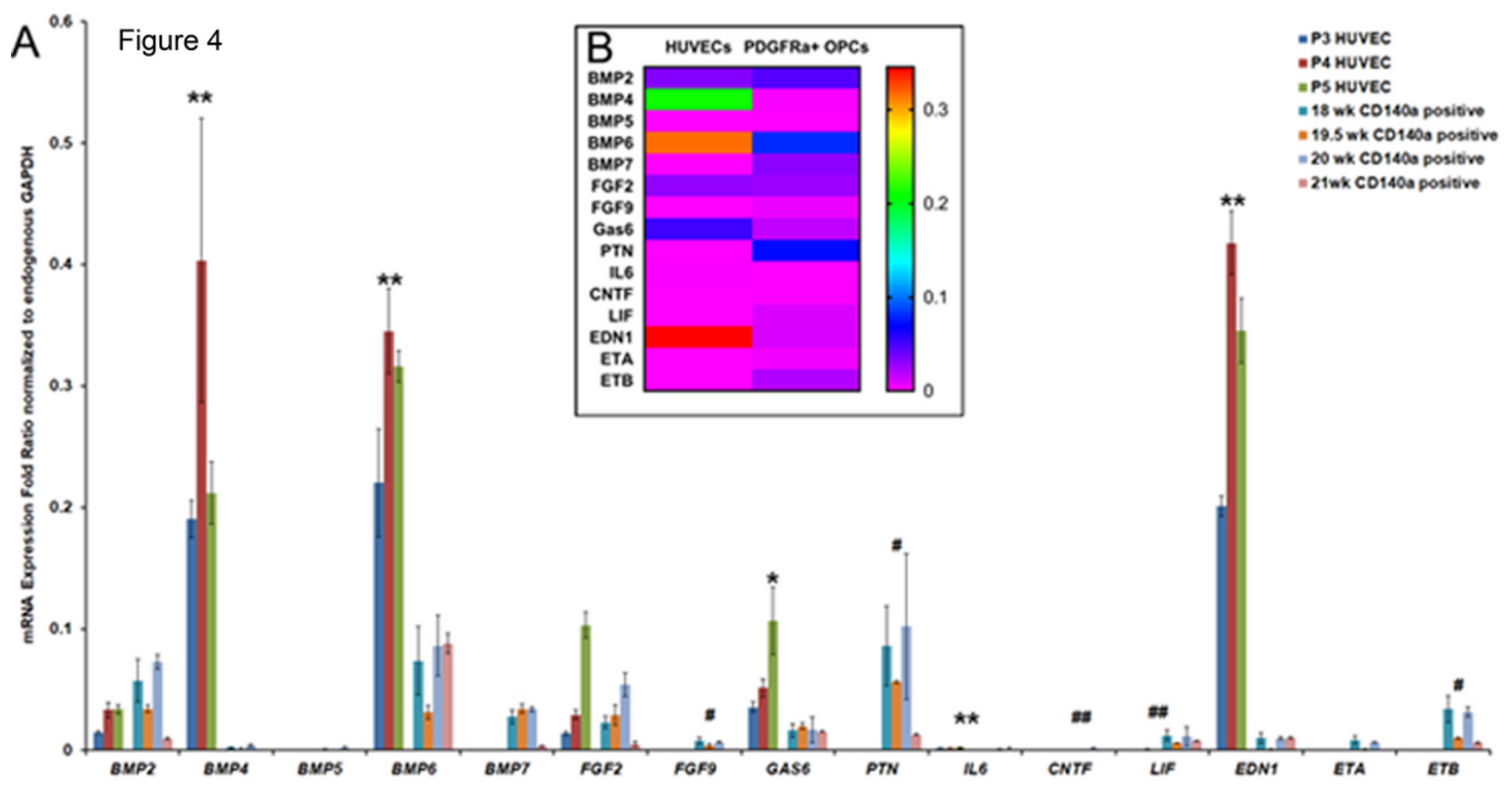

Figure 4

Gene expression profile by Taqman assay for selected soluble factors in HUVECs and PDGFRa+ hOPCs (A) Relative mRNA expression fold ratio of selected humoral factors with respect to endogenous GAPDH by Inventoried TaqMan® Gene Expression Assay are plotted as mean \pm SD for triplicate assays (technical replicates) for HUVEC ( $n=3$ biological replicates) and PDGFRa+ hOPCs ( $n=4$ biological replicates). Assays IDs are given in Supplemental Table S1. Statistical significance was determined by student's t-test for equal variance. Significant differences are indicated as* for $p<0.05$ and $* *$ for $p<0.01$, when the expression is significantly higher in HUVECs with respect to hOPCs; and as \# for $p<0.05$ and \#\# for $p<0.01$ when the expression is significantly higher in hOPCs with respect to HUVECs. Inset (B) shows the heat map of mean gene expression of biological replicates for the 15 genes assayed in HUVECs and 
PDGFRa+ hOPCs. Fold ratio of gene expression in HUVECs to PDGFRa+ hOPCs with respect to their respective endogenous GAPDH are given in Table 1. Raw Ct values for all Taqman assays are given in Supplemental Spreadsheet 1.

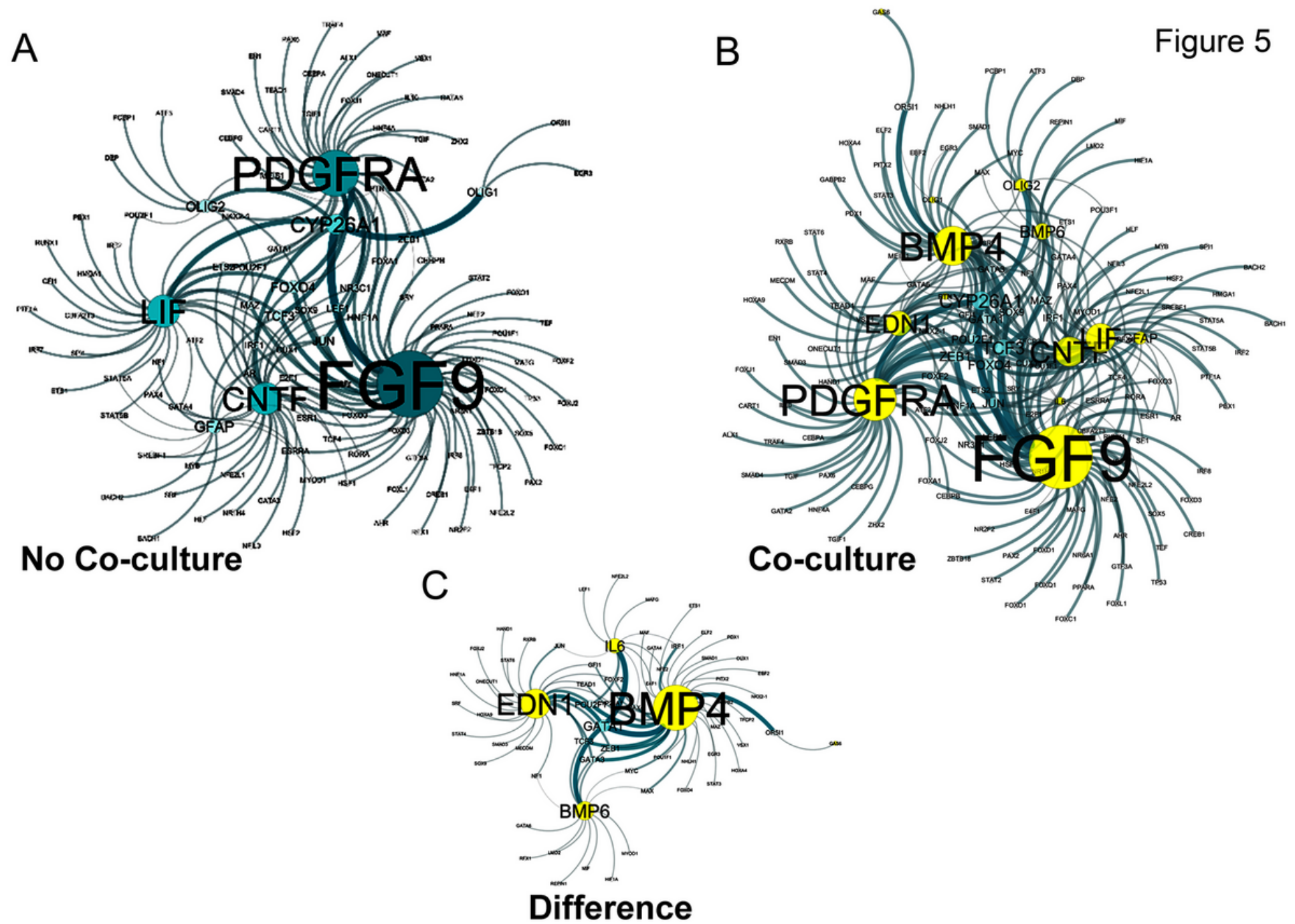

Figure 5

Differential network analysis reveals BMP4 as the key endothelial-derived soluble factor that influences the biology of the PDGFRa+ hOPCs during co-culture. Networks were generated for both no co-culture and with co-culture condition using the input gene lists for differential network analysis on the PCViz2 application, Pathway Commons. Network visualization, identification of major subnetworks and generation of difference network was done on Cytoscape 3.4.0. Input gene lists for differential network analysis are given in Supplemental Table S3. (A) Network for the No Co-culture condition. (B) Network for the Co-culture condition (C) Difference Network between the Co-culture and the No Co-culture conditiona. In all network diagrams, circles are larger for nodes with higher connectivity, and broader edges indicate stronger connections. For networks (B) and (C), nodes indicated by yellow circles are those provided in the input gene list. Complete list of nodes and edges for all three networks generated are given in Supplemental Spreadsheet 2. 


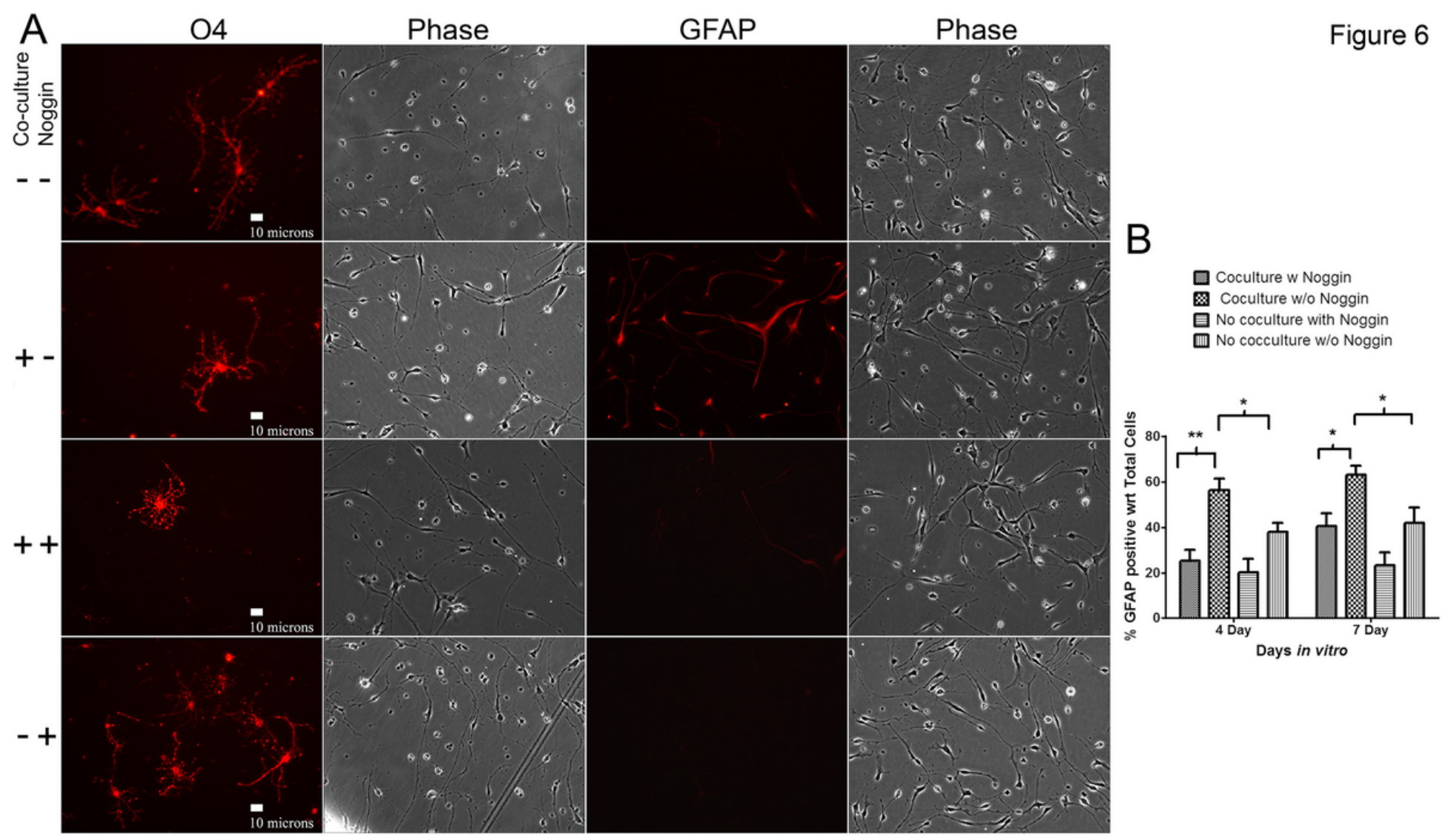

Figure 6

Noggin attenuates endothelial co-culture induced astrocytic differentiation of PDGFRa+ hOPCs (A) Representative micrographs for attenuation of HUVEC mediated astrocytic differentiation of PDGFRa+ hOPCs by $100 \mathrm{ng} / \mathrm{ml}$ Noggin (19.3 gw specimen). Complete attenuation of co-culture induced astrocytic differentiation by noggin indicates the differentiation to be BMP induced. Scale bar, 10 $\mu \mathrm{m}$. (B) Percent of GFAP positive cells after treatment with $100 \mathrm{ng} / \mathrm{ml}$ Noggin out of total cells counted in phase in ten random fields or 200 cells/well, plotted as mean \pm SE of counts from $n=4$ independent experiments (biological replicates) each with triplicate wells for with or without HUVEC co-culture. One-way ANOVA followed by Neuman-Keul's multiple comparison post-test was used for evaluating the effect of Noggin to attenuate astrocytic differentiation of hOPCs in co-culture. Post hoc $p$ values designated as * for $p<0.05$ and $* *$ for $p<0.01$. 


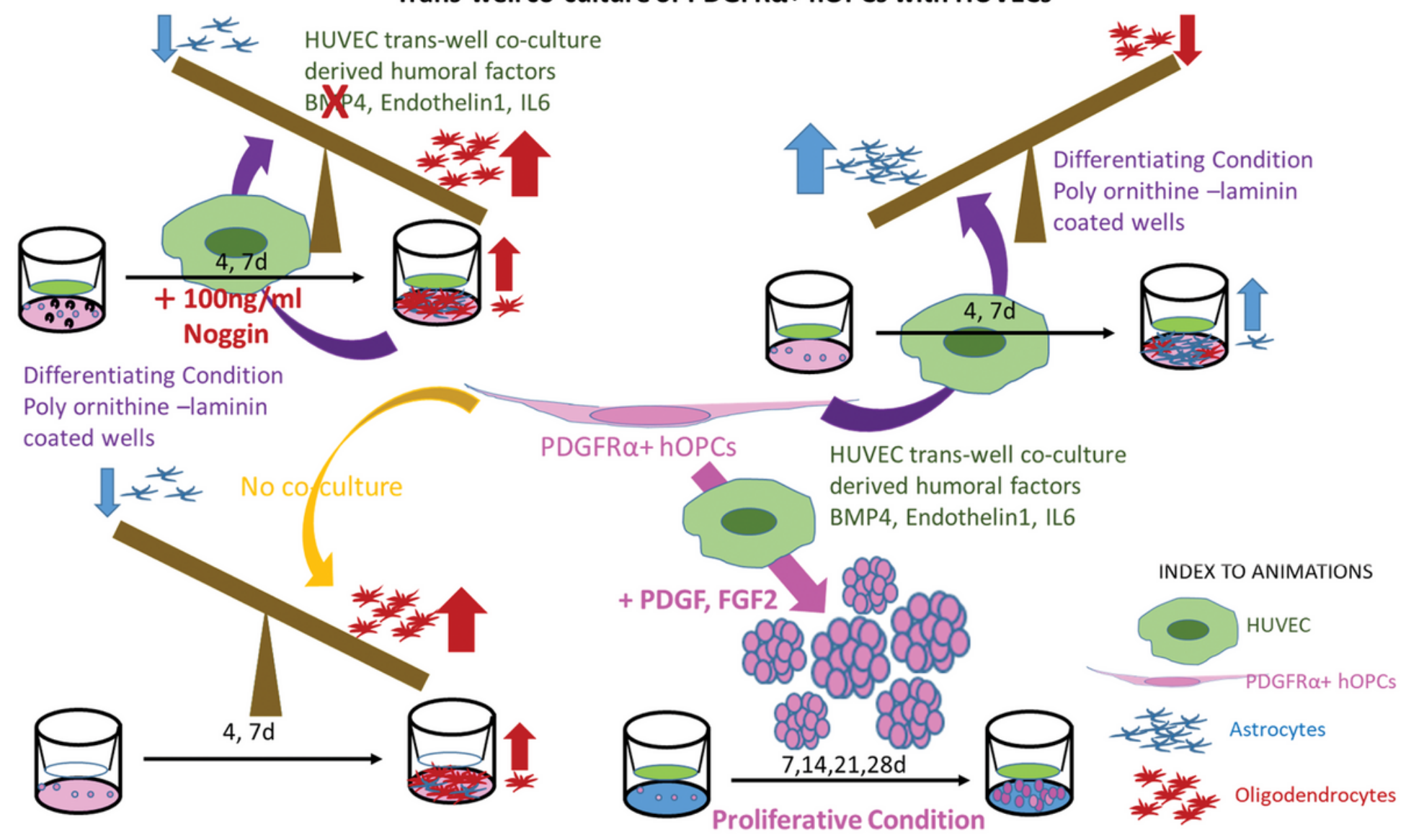

Figure 7

Effect of endothelial co-culture on PDGFRa+ human oligodendrocyte precursor cells (hOPCs). Trans-well co-culture of PDGFRa+ hOPCs in proliferative condition with human umbilical vein endothelial cells (HUVECs), leads to increased proliferation of these progenitors. Under differentiating conditions, the endothelial cells encourage BMP induced astrocytic differentiation of PDGFRa+ hOPCs as evidenced by complete attenuation of differentiation with noggin. The study also establishes the bi-potential nature of PDGFRa+ hOPCs.

\section{Supplementary Files}

This is a list of supplementary files associated with this preprint. Click to download.

- ADGSUPPLEMENTALINFORMATIONFebruary42022.docx

- ADGSupplementalSpreadsheet1February42022.xIsx

- ADGSupplementalSpreadsheet2February42022.xIsx 